\title{
DROSERACEAE DO PARQUE ESTADUAL DO IBITIPOCA, MINAS GERAIS, BRASIL
}

\author{
ROBERTO FERRERO \& RENATO DE MELLO-SILVA
}

\author{
Departamento de Botânica, Instituto de Biociências, Universidade de São Paulo, \\ Rua do Matão, 277, 05508-090 - São Paulo, SP, Brasil.
}

\begin{abstract}
Droseraceae from the Ibitipoca State Park, Minas Gerais, Brazil). The Droseraceae species inventory of the Ibitipoca State Park is presented. The Park is located in Mantiqueira Range, between $21^{\circ} 40^{\prime} 15^{\prime \prime}$ $-21^{\circ} 43^{\prime} 30^{\prime \prime} \mathrm{S}$ and $43^{\circ} 52^{\prime} 35^{\prime \prime}-43^{\circ} 54^{\prime} 15^{\prime \prime} \mathrm{W}$. Within the Park there are several types of vegetation, such as altitude savannas, montane forests and mostly campos rupestres. The Droseraceae, a cosmopolitan distributed family with three genera and about 150 species is represented in Brazil only by the genus Drosera with about 30 species. Four species occur in the Park: Drosera communis, D. montana, D. tomentosa var. glabrata and $D$. villosa. Key for the species, descriptions, illustrations and comments about distribution and taxonomy are presented.
\end{abstract}

Key words: Droseraceae, Drosera, Ibitipoca State Park, floristics, systematics.

Resumo - (Droseraceae do Parque Estadual do Ibitipoca, Minas Gerais, Brasil). Este trabalho apresenta o levantamento das Droseraceae do Parque Estadual do Ibitipoca. O Parque está situado na Cadeia da

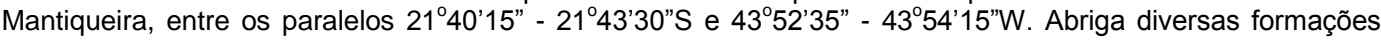
vegetais como cerrados de altitude, florestas montanas e principalmente campos rupestres. Droseraceae, uma família cosmopolita com três gêneros e cerca de 150 espécies, está representada no Brasil pelo gênero Drosera com cerca de 30 espécies. No Parque ocorrem quatro espécies: Drosera communis, $D$. montana, $D$. tomentosa var. glabrata e D. villosa. São apresentados chaves de identificação para as espécies, descrições, ilustrações e comentários sobre distribuição e taxonomia.

Palavras-chave: Droseraceae, Drosera, Parque Estadual do Ibitipoca, florística, sistemática.

\section{Introdução}

Droseraceae é uma família cosmopolita e engloba três gêneros: Aldrovanda, Dionaea e Drosera (Meimberg et al. 2000, Rivadavia et al. 2003). Dionaea e Aldrovanda são monotípicos (Cronquist 1981, Takhtajan 1997) e ocorrem, respectivamente, no sudeste dos Estados Unidos e na Europa, África, Índia, Japão e Austrália. Drosera possui cerca de 150 espécies e, embora cerca de $50 \%$ delas serem restritas ao sudoeste australiano, o gênero distribui-se por todos continentes, exceto Antártica (Juniper et al. 1989). No Brasil ocorrem cerca de 30 espécies distribuídas por todo o país, principalmente ao longo da Cadeia do Espinhaço e Mantiqueira, onde encontram-se cerca de 15 espécies, das quais ao menos três endêmicas de campos rupestres da região (Correa \& Silva 2005). O Parque Estadual do Ibitipoca, situado na Serra da Mantiqueira, apresenta $45 \%$ de sua área coberta por campos rupestres (Dias et al. 2002) e é considerado como área prioritária para a conservação da fauna e flora do Estado de Minas Gerais (Costa et al. 1998). No entanto, o turismo exerce grande pressão sobre a flora local (Ladeira et al. 2007), principalmente sobre aquelas espécies de hábito herbáceo, que são mais vulneráveis ao pisoteamento. Dentro deste contexto, este trabalho objetiva catalogar as espécies de Drosera do Parque, aumentando o conhecimento da diversidade na região e fornecendo subsídios para possíveis políticas de conservação da área.

\section{Material e Métodos}

A Serra do Ibitipoca, localizada no sudeste de Minas Gerais, nos municípios de Lima Duarte e Santa Rita do Ibitipoca, nas coordenadas $21^{\circ} 40^{\prime} 15^{\prime \prime}$ a $21^{\circ} 43^{\prime} 30$ "S e $43^{0} 52^{\prime} 35^{\prime \prime}$ a $43^{0} 54^{\prime} 15^{\prime \prime W}$, faz parte do Complexo da Mantiqueira e do Planalto de Andrelândia (Rodela \& Tarifa 2002), duas formações inseridas em domínios geomorfológicos distintos, a primeira formada por gnaisses e a segunda por quartzitos (Rodela 2000). No entanto, grande parte da Serra do Ibitipoca é composta por afloramentos de rochas quartzíticas (Rodela \& Tarifa 2002, Dias et al. 2002). Inserido na Serra do Ibitipoca está o Parque Estadual do Ibitipoca, com área de 1.488 ha e altitudes entre 1000 a 1784 m (Rodela \& Tarifa 2002). A vegetação da área abrange cerrado, florestas montanas e sub-montanas e, predominantemente, campos rupestres.

Materiais de coletas próprias e coleções, principalmente dos herbários BHCB, CESJ, RB e SPF (acrônimos segundo Thiers 2011) foram examinados. Materiais de outras localidades examinados foram utilizados para complementar as descrições de $D$. communis. As ilustrações foram confeccionadas com o auxilio de câmara clara acoplada a estereomicroscópio 
e as medidas foram feitas no sentido de maior largura e comprimento das estruturas. Considerou-se como pecíolo a parte da folha que não apresenta tentáculos glandulares. A delimitação das espécies utilizada segue Saint-Hilaire (1824a, b) e caracteres morfológicos de indumento foram descritos segundo Seine \& Barthlott (1993).

\section{Resultados e Discussão}

No Parque Estadual do Ibitipoca, as Droseraceae estão representadas por um gênero com quatro espécies: Drosera communis, D. montana, $D$. tomentosa var. glabrata e $D$. villosa.

Chave para as espécies de Drosera

1. Folhas $6-16 \mathrm{~cm}$ compr., eretas a ereto-patentes, ápice agudo 4. D. villosa

1'. Folhas 1-3 cm compr., adpressas ao solo, ápice obtuso ou arredondado.

2. Pecíolo ca. $1 / 2$ do comprimento total da folha, pedúnculo curvado na região proximal

2'. Pecíolo ca. 1/4 do comprimento total da folha, pedúnculo reto.

3. Limbo oblongo, face abaxial glabra a esparsamente pilosa

3'. Limbo obovado, face abaxial moderadamente pilosa 1. D. communis 2. D. montana 3. D. tomentosa var. glabrata

\section{Drosera L.}

Ervas insetívoras, perenes, acaules ou caulescentes. Folhas simples dispostas em rosetas, vináceas, obovadas ou oblongas, mais raramente lineares, cuneadas, face adaxial coberta por tentáculos, geralmente ambas as faces cobertas por tricomas. Estípulas presentes ou ausentes, laciniadas. Inflorescências monocásicas, com número de flores variável, às vezes com flores solitárias. Pedúnculos com pelos glandulares e pelos simples, às vezes glabros, um ou dois por roseta, raramente três. Brácteas lanceoladas, com tricomas glandulares. Flores diclamídeas, heteroclamídeas, actinomorfas, monoclinas. Sépalas 5, parcialmente unidas, com tricomas glandulares, raramente glabras. Pétalas 5 , geralmente róseas, às vezes brancas ou amarelas, persistentes, obovadas, ápice obtuso, glabras, às vezes marcescentes. Estames 5 , alternos às pétalas, eretos, filetes glaucos, anteras bitecas, amarelas, de deiscência longitudinal. Ovário súpero 3-5-carpelar, unilocular; placentação parietal; estiletes 3 , inteiros ou partidos desde a base, ou 5 inteiros, óvulos numerosos. Frutos capsulares, 3-5valvares. Sementes oblongas a elipsóides, testa reticulada ou papilosa.

1. Drosera communis A.St.-Hil., Pl. usuel. bras. 1(3): 1.1824.

Fig. $1 \mathrm{~A}-\mathrm{C}$

Ervas $5-10 \mathrm{~cm}$ alt. Folhas adpressas ao solo; pecíolo 2-5 $\mathrm{mm}$ compr., glabro a esparsamente piloso; limbo 2-4 mm compr., 1-2 $\mathrm{mm}$ larg., obovado ou oblanceolado, ápice obtuso, face abaxial glabra; estípulas 1-3 mm compr. Pedúnculo 4-10 cm compr., curvado na região proximal, terço proximal esparsamente piloso, região mediana glabra, terço distal coberto por tricomas glandulares, brácteas ca. $1 \mathrm{~mm}$ compr. Flores 1-8, pedicelos 1-3 $\mathrm{mm}$ compr.; sépalas $3-4 \mathrm{~mm}$ compr.; pétalas 6-7 $\mathrm{mm}$ compr., róseas; filetes 2-3 $\mathrm{mm}$ compr., anteras ca. 0,5 mm compr. Gineceu tricarpelar; ovário 1-2 $\mathrm{mm}$ compr.; estiletes 3, 2-3 mm compr., bifurcados desde a base. Frutos 3-valvares, sementes fusiformes, testa reticulada.

Material examinado: brejo logo acima da Gruta do Monjolinho, 29.X.1995 (st), F. Rivadavia-Lopes et al. 506 (SPF).

Material adicional: MINAS GERAIS: Diamantina, estrada que passa pela Gruta do Salitre, 12.V.2007 (fl), F. Rivadavia-Lopes 2519 (SPF). SANTA CATARINA: Alfredo Wagner, Km 111 da $\mathrm{Br}$ 282, 27.IV.2007 (fl), F. RivadaviaLopes 2505 (SPF).

Drosera communis tem ampla distribuição na América do sul, da Colômbia ao sul do Brasil. Cresce em lugares abertos e úmidos (Correa \& Silva 2005). Em Ibitipoca ocorre em pequenas populações ou indivíduos isolados, frequentemente em meio a gramíneas.

2. Drosera montana A.St.-Hil., Hist. plant. remarq. Brésil 1:260. 1824.

Fig. 2 D-F.

Ervas $8-14 \mathrm{~cm}$ alt. Folhas adpressas ao solo; pecíolo 1-4 $\mathrm{mm}$ compr., glabro a esparsamente piloso; limbo 0,5-1,5 cm compr., 2-4 mm larg., oblongo, ápice obtuso, face abaxial esparsamente pilosa ou glabra; estípulas 2-4 mm compr. Pedúnculo 7-14 cm compr., 1-2 por roseta, raramente 3-4, ereto, terço proximal esparsamente piloso ou glabro, região mediana e terço distal cobertos por tricomas glandulares, mais densamente em direção ao ápice, brácteas ca. $1 \mathrm{~mm}$ compr. Flores 2-6, pedicelos 3-5 mm compr.; sépalas 2-6 $\mathrm{mm}$ compr.; pétalas 3-6 $\mathrm{mm}$ compr., róseas; filetes 2-4 $\mathrm{mm}$ compr., anteras ca. $1 \mathrm{~mm}$ compr. Gineceu tricarpelar; ovário 1-2 mm compr.; estiletes 3, 2-4 mm compr., bifurcados desde a base. Frutos 3-valvares, sementes obovais a elipsoides, testa reticulada.

Material examinado: Pico do Pião, 14.V.1970 (fl), D. Sucre 6857 (RB); $6 . I I .1989$ (fl), L.T. Souza \& L. Krieger s.n. (CESJ 24296, R); Monjolinho, 19.V.1991 (fl, fr), M. Brügger et 


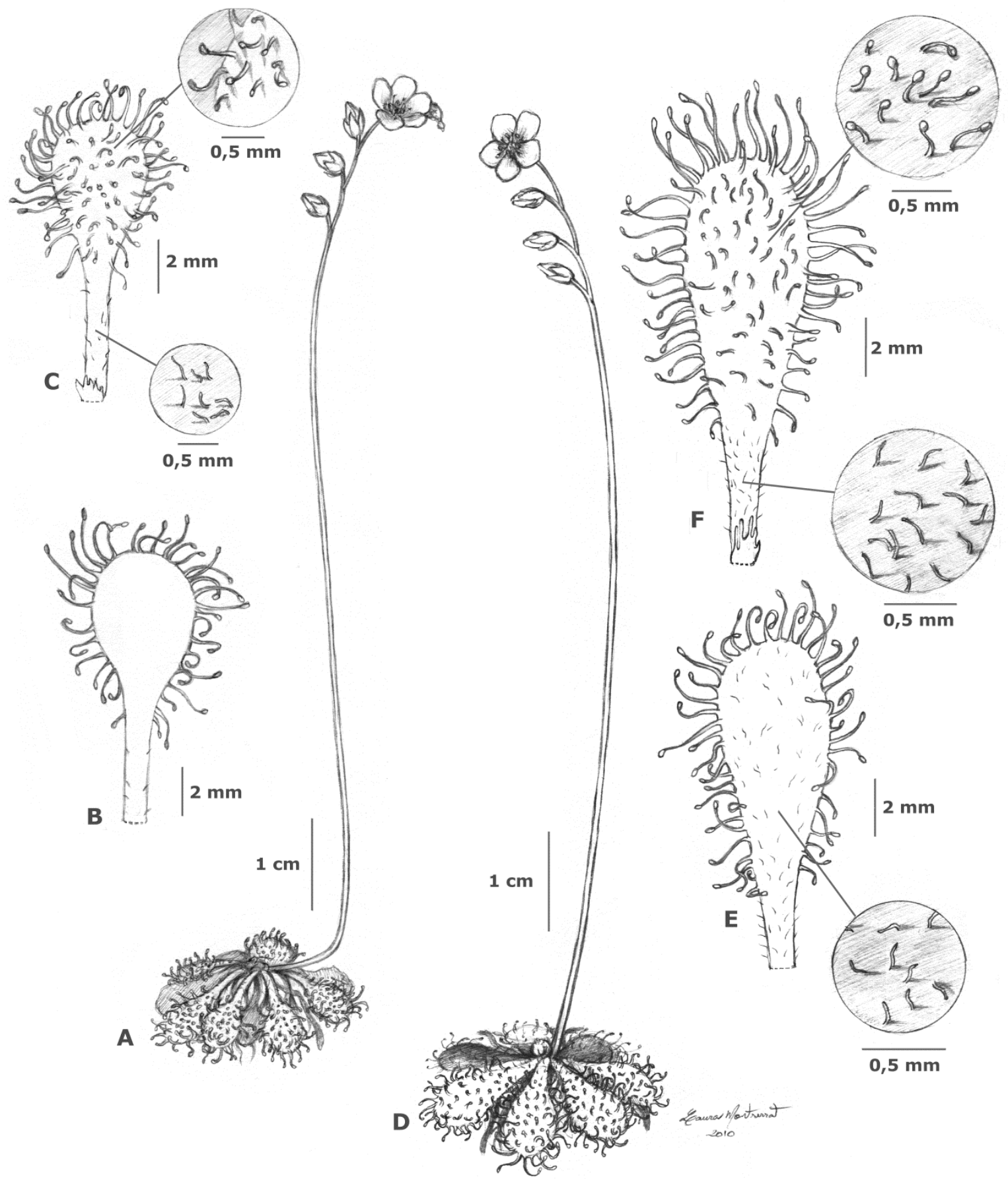

Fig.1. A-C. Drosera communis: A. hábito com flores; B. folha, face abaxial; C. folha, face adaxial, mostrando detalhes do indumento. D-F. Drosera tomentosa var. glabrata: D. hábito com flores; E. folha, face abaxial, mostrando detalhes do indumento; F. folha, face adaxial, mostrando detalhes do indumento. (A-C: RivadaviaLopes 506; D-F: Rivadavia-Lopes 1955). 
al. s.n. (CESJ 24659); próximo ao Cruzeiro, 27.VII.1991 (fl), M. Eiterer s.n. (CESJ 24874); trilha para a Gruta do Monjolinho, 29.X.1995 (fl), F. Rivadavia-Lopes et al. 504 (SPF); trilha para a Lombada, 8.II.2001 (fl), R.C. Forzza et al. 1783 (CESJ); ao lado da estrada entre a entrada do Parque e o acampamento, 23.XI.2001 (fl), F. Rivadavia-Lopes 1321 (SPF); ao lado da trilha para o Pico do Pião, 24.XI.2001 (fl), F. Rivadavia-Lopes 1330 (SPF); ao lado da estrada entre a entrada do Parque e o centro de visitantes, 26.II.2005 (fl), F. Rivadavia-Lopes 1953 (SPF); trilha ente Lago dos Espelhos e Monjolinho, 18.IX.2007 (fl), R. C. Forzza 4714 (RB); trilha para o Pico do Pião, cerca de $500 \mathrm{~m}$ após a prainha, 25.I.2010 (fl), R. Ferrero et al. 1 (SPF).

Drosera montana ocorre em cerrados de altitude da Bahia a Santa Catarina (Silva \& Giulietti 1997). Em Ibitipoca ocorre em grandes populações, frequentemente em barrancos na beira de trilhas. Cresce em solos úmidos, às vezes encharcados, frequentemente associada a Sphagnum. A coloração vinácea das folhas pode ser substituída por verde em indivíduos que crescem na sombra.

3. Drosera tomentosa var. glabrata A.St.-Hil., Hist. plant. remarq. Brésil 1: 262. 1824.

Fig. 1 D-F

Ervas $10-17 \mathrm{~cm}$ alt. Folhas adpressas ao solo; pecíolo 1-3 mm compr., moderadamente piloso, limbo 0,5-1,5 cm compr., 4-7 mm larg., obovado, ápice obtuso ou arredondado, face abaxial moderadamente a densamente pilosa; estípulas 2-4 mm. Pedúnculo 7-15 cm compr., terço proximal glabro a esparsamente piloso, restante coberto por tricomas glandulares, mais densamente em direção ao ápice, brácteas ca. $1 \mathrm{~mm}$ compr. Flores 3-7, pedicelos 3-6 mm compr.; sépalas 2-4 $\mathrm{mm}$ compr.; pétalas 3-5 $\mathrm{mm}$ compr., róseas; filetes 2-3 $\mathrm{mm}$ compr., anteras ca. $1 \mathrm{~mm}$ compr. Gineceu tricarpelar; ovário 1-2 mm compr.; estiletes 3, 2-3 mm compr., bifurcados desde a base. Frutos 3-valvares, sementes obovais a elipsoides, testa reticulada.

Material examinado: 16.VII.1977 (fl), M. Brügger 1760 (CESJ, R); $15 . X .1986$ (fl), H.C. Souza et al. s.n. (BHCB); perto da Lagoa Seca, 8.X.1987 (fl), P. Andrade 1049 (BHCB); caminho do Mojolinho, 12.IX.1991 (fl), S.M.S. Verardo s.n. (BHCB, CESJ 25371, SPF); próximo à Prainha, 18.VII.1992 (fl), F. Rivadavia-Lopes 141 (SPF); 28.VIII.1993 (fl, fr), F.R. Salimena-Pires s.n. (CESJ 26786); 23.XII.2000 (fl, fr), M.A. Heluey 10 (CESJ, MBM); trilha para o Morro da Lombada, 24.XI.2001 (fl), F. Rivadavia-Lopes 1324 (SPF); trilha entre a Cachoeirinha e o Pico do Pião, 24.XI.2001 (fl), $F$ Rivadavia-Lopes 1329 (SPF); trilha subindo o Morro da Lombada, 26.II.2005 (fl), F. Rivadavia-Lopes 1955 (SPF).

Drosera tomentosa var. glabrata ocorre em serras de Minas Gerais, em áreas de campos rupestres (Silva \& Giulietti 1997). Em Ibitipoca ocorre em grandes populações frequentemente em barrancos na beira de trilhas. Cresce em solos úmidos, às vezes encharcados, frequentemente associada a Sphagnum.
4. Drosera villosa A.St.-Hil., Hist. plant. remarq. Brésil 1: 267. 1824.

Fig. $2 \mathrm{~A}-\mathrm{C}$

Ervas 10-25 cm alt. Folhas ascendentes; pecíolo 2-4 cm compr., densamente piloso, limbo 4- 12 cm compr., 2-5 mm larg., linear, ápice agudo, face abaxial densamente pilosa; estípulas 2-4 mm compr. Pedúnculo 9- $25 \mathrm{~cm}$ compr., terço proximal densamente piloso, região mediana glabra e terço distal coberto por tricomas glandulares; brácteas $1 \mathrm{~mm}$ compr. Flores 4-10, pedicelos 3-5 $\mathrm{mm}$ compr.; sépalas 4-6 mm compr.; pétalas $6-8 \mathrm{~mm}$ compr., róseas; filetes $3-4 \mathrm{~mm}$ compr., anteras 1-2 mm compr. Gineceu tricarpelar; ovário 1-2 mm compr.; estiletes 3, 2-5 mm compr., bifurcados desde a base. Frutos 3-valvares, sementes fusiformes, testa reticulada.

Material examinado: 1.X.1970 (st), U. Confúcio s.n. (CESJ 9441); 5.V.1987 (fl), P. Andrade 960 (BHCB); trilha para o Cruzeiro, 27.VII.1991 (st), M. Eiterer et al. s.n. (CESJ 24862); Morro da Lombada, 20.VII.1992 (fl), F. RivadaviaLopes 143 (SPF); Lagoa Seca, 10.XII.2000 (fl), M.A. Heluey 17 (CESJ, MBM); trilha entre a Gruta do Cruzeiro e a Lombada, ca. de $500 \mathrm{~m}$ após a Gruta, 26.I.2010 (fl, fr), $R$. Ferrero et al. 2 (SPF).

Drosera villosa ocorre em serras de Minas Gerais a Santa Catarina, principalmente em áreas de campos rupestres. No sul de São Paulo e em Santa Catarina pode ocorrer em áreas de mata, mas nunca em locais sombreados (Silva \& Giulietti 1997). Em Ibitipoca, ocorre em grandes populações frequentemente em barrancos e áreas úmidas. Cresce em solos úmidos, às vezes encharcados, frequentemente associada a Sphagnum.

\section{Conclusões}

Apesar de intensamente estudadas, as Droseraceae brasileiras ainda são objeto de disputas. No tratamento das espécies de Ibitipoca, os caracteres reprodutivos, exceto o pedúnculo da inflorescência, não foram utilizados na distinção dos táxons por serem uniformes entre as populações que ocorrem no parque. Os caracteres foliares, no entanto, são distintos e característicos de cada táxon, tendo sido suficientes para diagnosticá-los. Por isto, as delimitações taxonômicas seguem as propostas de Saint-Hilaire $(1824 a, b)$ e estão em desacordo com a mais recente revisão (Correa \& Silva 2005), onde os aspectos morfológicos foliares são ignorados e os táxons são delimitadas por caracteres altamente polimórficos de indumento do pedúnculo.

\section{Agradecimentos}

Trabalho desenvolvido no programa de Iniciação Científica da Universidade de São Paulo. Os autores agradecem aos herbários citados pelo envio ou empréstimo de material, ao Instituto Estadual de 


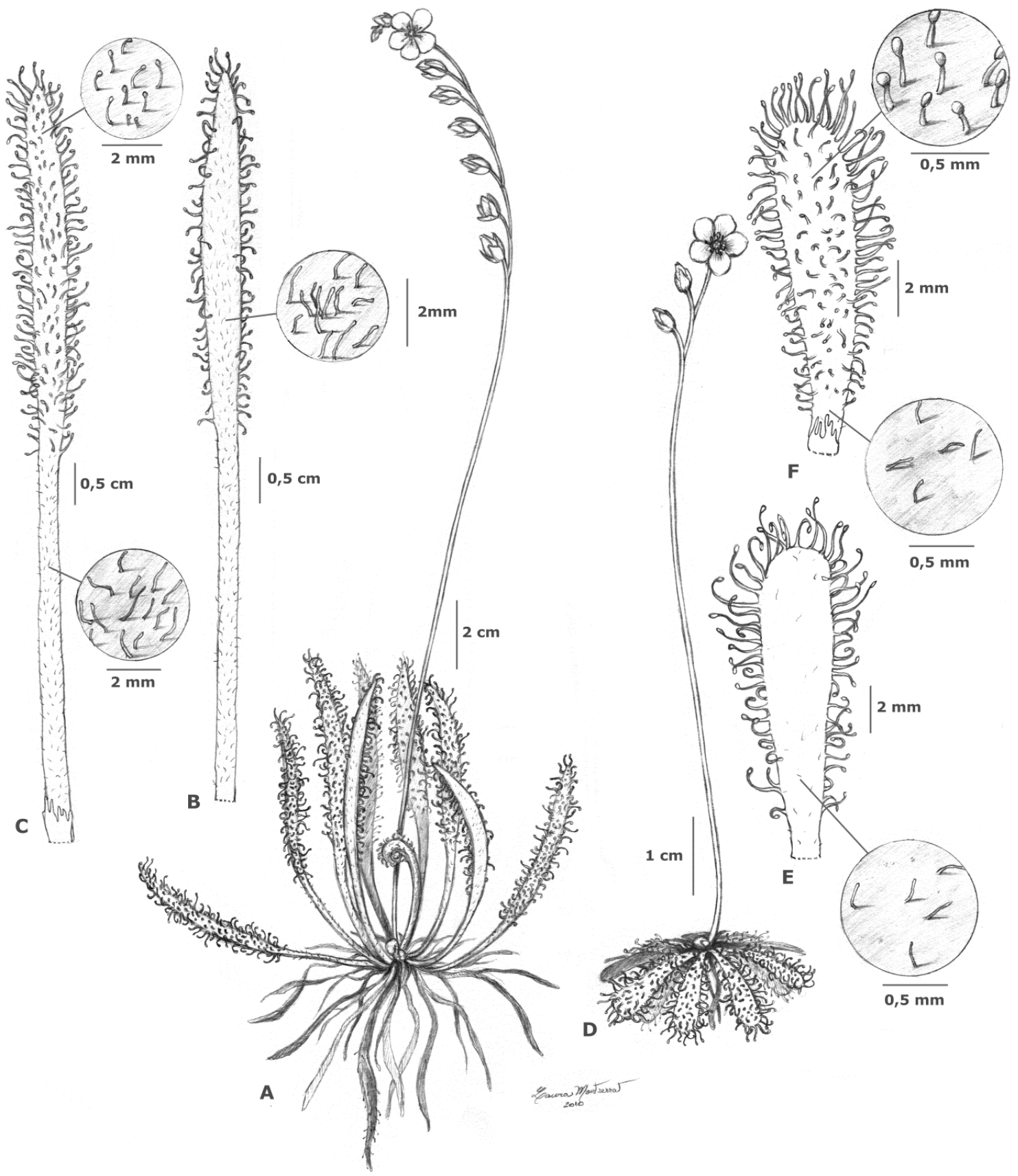

Fig. 2. A-C. Drosera villosa: A. hábito com flores e frutos; B. folha, face abaxial, mostrando detalhes do indumento; C. folha, face adaxial, mostrando detalhes do indumento. D-F. Drosera montana: D. hábito com flores; E. folha, face abaxial, mostrando detalhes do indumento; F. folha, face adaxial, mostrando detalhes do indumento. (A-C: Ferrero 2; D-F: Ferrero 1). 
Florestas de Minas Grais pelo apoio aos trabalhos em Ibitipoca e a dois assessores pelas sugestões. As ilustrações foram confeccionadas por Laura Montserrat. Roberto Ferreiro teve bolsa de Iniciação Científica do PIBIC/CNPq e Renato de Mello-Silva é bolsista de Produtividade em Pesquisa do CNPq.

\section{Referências}

CORREA, M.D. \& SILVA, T.R.S. 2005. Drosera (Droseraceae). Fl. Neotr. Monogr. 96: 1-60.

COSTA, C.M.R., HERRMANN, G., MARTINS, C.S., LINS, L.V. \& LAMAS, I.R. 1998. Biodiversidade em Minas Gerais: um atlas para sua conservação. Fundação Biodiversitas. Belo Horizonte.

CRONQUIST, A. 1981. An Integrated system of classification of flowering plants. Columbia University Press. New York.

DIAS, H.C.T., FILHO, E.I.F., SCHAEFER, C.E.G.R. FONTES, L.E.F \& Ventorim, L.B. 2002. Geoambientes do Parque Estadual do Ibitipoca, município de Lima Duarte-MG. Rev. Árvore 26(6): 777-786.

JUNIPER, B.E., ROBINS R.J. \& JOEL, D.M. 1989. The carnivorous plants. Academic Press. London.

LADEIRA, A.S., RIBEIRO, G.A., DIAS, H.C.T., SCHAEFER, C.E.G.R., FILHO, E.F. \& OLIVEIRAFILHO, A.T. 2007. O perfil dos visitantes do Parque Estadual do Ibitipoca (PElb), Lima Duarte, MG. Rev. Árvore 31(6): 1091-1098.
MEIMBERG, H., DITTRICH, P., BRINGMANN, G., SCHLAUER, J. \& HEUBL, G. 2000. Molecular phylogeny of Caryophyllidae s. I. based on matK sequences with special emphasis on carnivorous taxa. Plant Biol. 2(2): 218-228.

RIVADAVIA, F., KONDO, K., KATO, M. \& HASEBE, M. 2003. Phylogeny of the sundews, Drosera (Droseraceae), based on chloroplast $\mathrm{rbcL}$ and nuclear 18S ribosomal DNA sequences. Amer. J. Bot. 90(1): 123-130.

RODELA, L.G. 2000. Distribuição de campos rupestres e cerrados de altitude na Serra do Ibitipoca, sudeste de Minas Gerais. Dissertação de Mestrado. Universidade de São Paulo. São Paulo.

RODELA, L.G. \& TARIFA, J.R. 2002. O clima na Serra do Ibitipoca, sudeste de Minas Gerais. GEOUSP Espaço e Tempo 11: 101-113.

SAINT-HILAIRE, A.F.C.P. 1824a. Histoire des plantes les plus remarquables du Brésil et du Paraguay. A. Belin. Paris.

SAINT-HILAIRE, A.F.C.P. 1824b. Plantes usuelles des brasiliens. Grimbert. Paris.

SEINE, R. \& BARTHLOTT, W. 1993. On the morphology of trichomes and tentacles of Droseraceae Salisb. Beitr. Biol. Pflanzen 67: 345-366.

SILVA, T.R.S. \& GIULIETTI, A.M. 1997. Levantamento das Droseraceae do Brasil. Bol. Bot. Univ. São Paulo 16: 75105.

TAKHTAJAN, A. 1997. Diversity and classification of flowering plants. Cambridge University Press. New York.

THIERS, B. 2011 [continuously updated]. Index herbariorum: A global directory of public herbaria and associated staff. New York Botanical Garden's Virtual Herbarium. http://sweetgum.nybg.org/ih/ (21 Abr 2011) 